\title{
Some remarks on the seismic design of multipropped retaining walls
}

\author{
Fabio M. Soccodato*, Giuseppe Tropeano and Alessandro Aru \\ Dept. of Civil, Environmental Engineering and Architecture (DICAAR), Università di Cagliari \\ Via Marengo 2, 90123, Cagliari (Italy) \\ soccodato@unica.it
}

\begin{abstract}
The behavior under seismic condition of embedded retaining structures is quite complex. When the geometry (prop levels) prevents the formation of kinematic mechanisms and the structural elements do not achieve yield strength conditions, permanent displacements are expected to be relatively low and, therefore, seismic actions may cause significant increases of the forces acting on the structures: these forces are dependent on a number of factors such as the characteristics of the ground motion, the problem geometry, the mechanical behavior of the soil and the soil-structure relative stiffness. In the present study, the results of several dynamic numerical analyses of a multi-propped retaining wall in a dry coarse soil are presented and discussed. The results of the analyses indicate that large structural stresses (bending moments in walls and axial loads on props) develop as consequence of seismic actions. Post seismic stresses remain significantly large as compared to the static condition. The maximum ground acceleration in the free-field seems not to be an effective parameter in order to evaluate the seismic performance of this kind of retaining structures.
\end{abstract}

Keywords: retaining structures, dynamic analyses, soil-structure interaction

\section{Introduction}

The behavior under seismic condition of embedded, flexible retaining structures is quite complex. Furthermore, data obtained from experimental studies on physical models refer generally to cantilevered walls or with a single level of prop at the top of the wall (Conti et al, 2012). In these cases, the formation of an instantaneous kinematic mechanism (rigid motion) due to the complete mobilization of the soil resistance, both behind and in front of the wall, is possible. Seismic energy is dissipated in the accumulation of permanent displacements of the structure, due to plastic soil straining and the phenomenon can be interpreted in the framework of the displacements methods (rigidblock model), by evaluating the critical acceleration that triggers the collapse mechanism (Callisto and Soccodato, 2010).

When the geometry of the levels of props prevents the formation of kinematic mechanisms and the structural elements do not achieve yield strength conditions, permanent displacements are expected to be relatively low and, therefore, seismic actions may 
cause significant increases of the forces acting on the structures: these forces are dependent on a number of factors such as the characteristics of the ground motion, the problem geometry, the mechanical behavior of the soil and the soil-structure relative stiffness. Numerical studies about this topic are quite limited; significant increments of structural actions, also in a post-seismic condition, have been obtained from dynamic numerical analyses (Tropeano and Soccodato, 2014; Chowdhury et al, 2015; Bahrami et al, 2019).

In this study, the preliminary results of a set of dynamics numerical analyses of a pair of multipropped, embedded retaining walls in a dry coarse-grained soils are presented and discussed, with the aim to furnish a contribution to the understanding of the behavior of this kind of structures under seismic loading.

\section{Numerical model}

Numerical dynamic analyses were carried out, under plane strain conditions, with the finite difference code FLAC (Itasca, 2011), with reference to a soil model already considered by Callisto and Soccodato (2010) and Tropeano and Soccodato (2014). It consists of a layer of dry coarse-grained soil, $30 \mathrm{~m}$ in thickness, resting upon a rigid bedrock. The geometry and the computation grid are shown in Fig. 1. The pair of walls $(L=12 \mathrm{~m})$, with three prop levels, sustains an excavation of height $H=8 \mathrm{~m}$ and width $16 \mathrm{~m}$.

An elastic perfectly plastic model with a Mohr-Coulomb strength rule, characterized by mechanical properties corresponding to those of a medium sand was adopted. The shear stiffness at small strains, $G_{0}$, is calculated as a function of mean effective stress, $p^{\prime}$, with the relation:

$$
G_{0}=K_{G} \sqrt{\frac{p^{\prime}}{p_{r e f}}}
$$

where $p_{\text {ref }}$ is a reference pressure $(100 \mathrm{kPa})$ and $K_{G}$ is a stiffness coefficient set equal to 1000. The soil hysteretic behavior was modeled adopting the shear modulus decay curves for sands given by Seed and Idriss (1970) and by applying the generalized Masing criteria implemented (sig4 model) in the computer code used in this study. As for the other soil parameters, the soil unit weight was set equal to $20 \mathrm{kN} / \mathrm{m}^{3}$ and the Poisson' ratio equal to 0.2 . The friction angle was assumed equal to $30^{\circ}$, with a small amount $(0.5 \mathrm{kPa})$ of cohesion in order to enhance numerical stability; finally, the coefficient of earth pressure at rest was set equal to 0.5 .

The maximum size of computation mesh elements has been fixed in order to allow the correct propagation of harmonics with a $15 \mathrm{~Hz}$ maximum frequency, which is the maximum frequency of the seismic signals adopted in this study, according to Lysmer and Kuhlemeyer (1973). To minimize reflection effects on vertical lateral boundaries of the grid, free field boundary conditions available in FLAC library have been used. 
A top-down construction technique was assumed, with the top and the intermediate restrain levels installed before each excavation stage. The installation of the bottom level ends the static stage of the analyses, which was carried out by adopting an elastic soil stiffness equal to $30 \%$ of the small strain one (Eq. (1)).

Two bending stiffness, EI, were adopted for the linear elastic beams simulating the retaining walls $\left(E I=2.7 \times 10^{5}\right.$ and $8.5 \times 10^{6} \mathrm{kN} \mathrm{m}^{2} / \mathrm{m}$ for a relatively flexible and a relatively stiff walls, respectively); elasto-plastic interface elements, with a friction angle equal to $20^{\circ}$, connect the walls to the soil. Props are characterized by an axial stiffness, $E A$, equal to $7.0 \times 10^{5} \mathrm{kN} / \mathrm{m}$.

The acceleration time histories used in the dynamic analyses (Fig. 2a) are records of three well known strong-motion earthquakes: Tolmezzo (TMZ), Assisi (ASS) and Gilroy (GLR). They are characterized by quite different frequency contents (Fig. 2b) but by about the same Arias intensity values. Additional seismic input (S02 and S03) were obtained by scaling the reference recordings S01. Tab. 1 summarizes peak accelerations. $a_{\mathrm{MAX}}$, and Arias intensities, $I_{A}$, applied at the bedrock (B) and the corresponding ones obtained from the dynamic analyses at ground surface in the free-field condition $(\mathrm{FF})$.

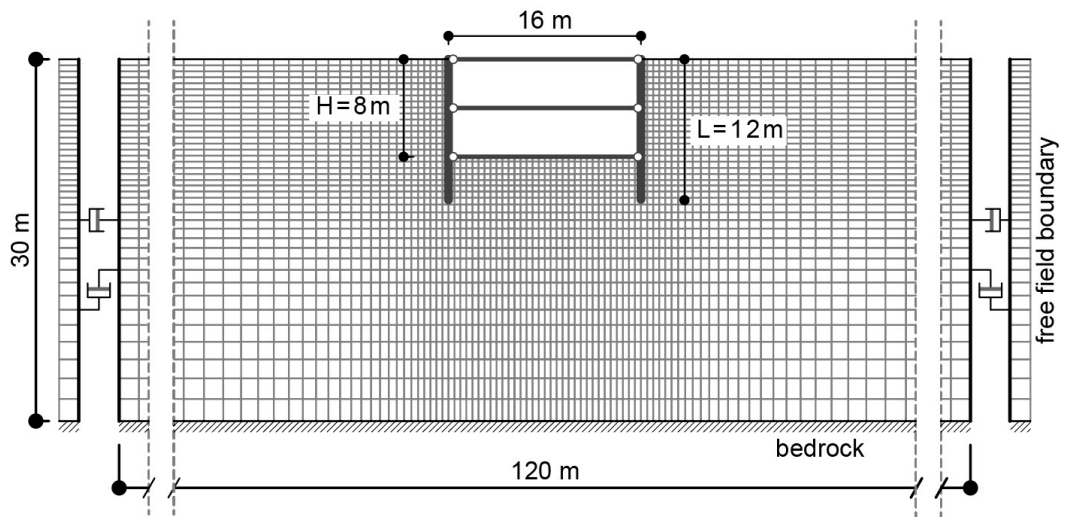

Fig. 1 Geometry of the numerical model $(L=12 \mathrm{~m})$

(a)

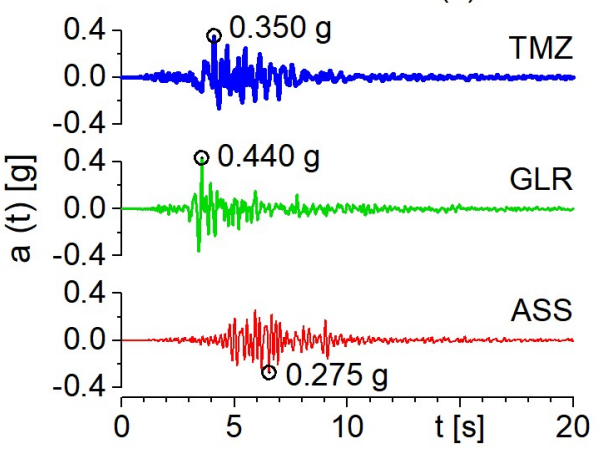

(b)

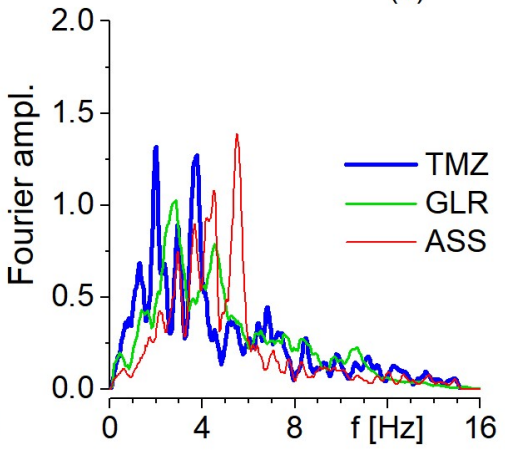

Fig. 2 Seismic input: a) acceleration time histories; b) frequency content 
Table 1 Input (bedrock, B) and output (free field, FF) seismic parameters

\begin{tabular}{ccccc}
\hline Signal & $a_{\mathrm{MAX}, \mathrm{B}}(\mathrm{g})$ & $I_{A, B}(\mathrm{~m} / \mathrm{s})$ & $a_{\mathrm{MAX}, F F}(\mathrm{~g})$ & $I_{A, F F}(\mathrm{~m} / \mathrm{s})$ \\
\hline TMZ-S03 & 0.150 & 0.146 & 0.209 & 0.885 \\
TMZ-S02 & 0.250 & 0.406 & 0.304 & 1.598 \\
TMZ-S01 & 0.350 & 0.798 & 0.349 & 2.317 \\
GLR-S03 & 0.189 & 0.128 & 0.252 & 0.628 \\
GLR-S02 & 0.314 & 0.356 & 0.309 & 1.167 \\
GLR-S01 & 0.440 & 0.770 & 0.326 & 1.610 \\
ASS-S03 & 0.118 & 0.138 & 0.245 & 0.991 \\
ASS-S02 & 0.196 & 0.382 & 0.285 & 1.747 \\
ASS-S01 & 0.275 & 0.752 & 0.313 & 2.492 \\
\hline
\end{tabular}

The effects of nonlinear seismic response of the $1 \mathrm{D}$ soil column to the different acceleration histories are clearly apparent when comparing input (at bedrock) and output (at surface) values.

A number of pseudo-static analyses were also carried out by progressively increasing the horizontal acceleration in the whole mesh.

\section{Results and discussion}

Structural stresses acting on walls and props (bending moment, $M$ and axial load, $N$ ) at the end of excavation are shown in Fig. 3, for both the flexible and stiff wall configuration. Structural actions are higher in the stiff structure than in the flexible one.

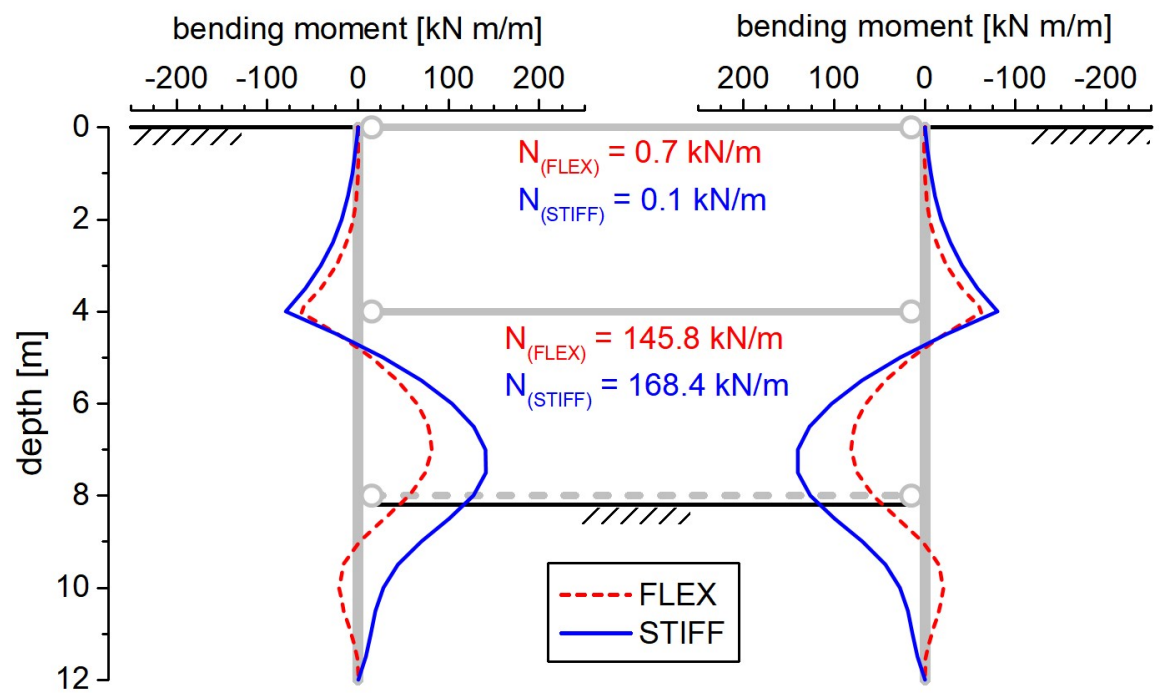

Fig. 3 Structural actions at the end of excavation 
The top prop is almost unloaded. The bottom prop is added at the end of the excavation: hence, seismic actions will act on a different structural scheme (3 restraint levels).

During seismic loading, soil stresses and structural actions vary very rapidly. Structural actions tend to increase, reaching a peak (max and min) value during strong motion. At the end of the earthquake, post seismic (residual) values of the structural action are significantly higher than those related to the static conditions.

Post-processing the results of dynamic analyses is a quite difficult due to the large amount of data. A dedicated routine was thus developed in order to extract and depict in an effective way the time evolution of soil stresses and structural actions.

A typical post processing results of the dynamic analyses is shown in Fig. 4, which represents bending moments in static and in post-seismic conditions together with bending moments envelops (max and min reached values), for both the flexible and stiff walls configuration and the TMZ-S02 earthquake. For comparison, in Fig. 4 is also represented the distribution of bending moments resulting from the pseudo-static analysis carried out with a (constant) horizontal acceleration equal to the peak ground acceleration in the free-field obtained from the dynamic analysis $\left(k_{H}=a_{\mathrm{MAX}, F F}\right)$. It appears, in this case, that peak structural actions obtained from the dynamic analyses are higher than those obtained from the pseudo-static analyses. Large bending moments in the embedded length of walls develop during strong motion stage. Post seismic stresses on structures are well above the initial, static values.

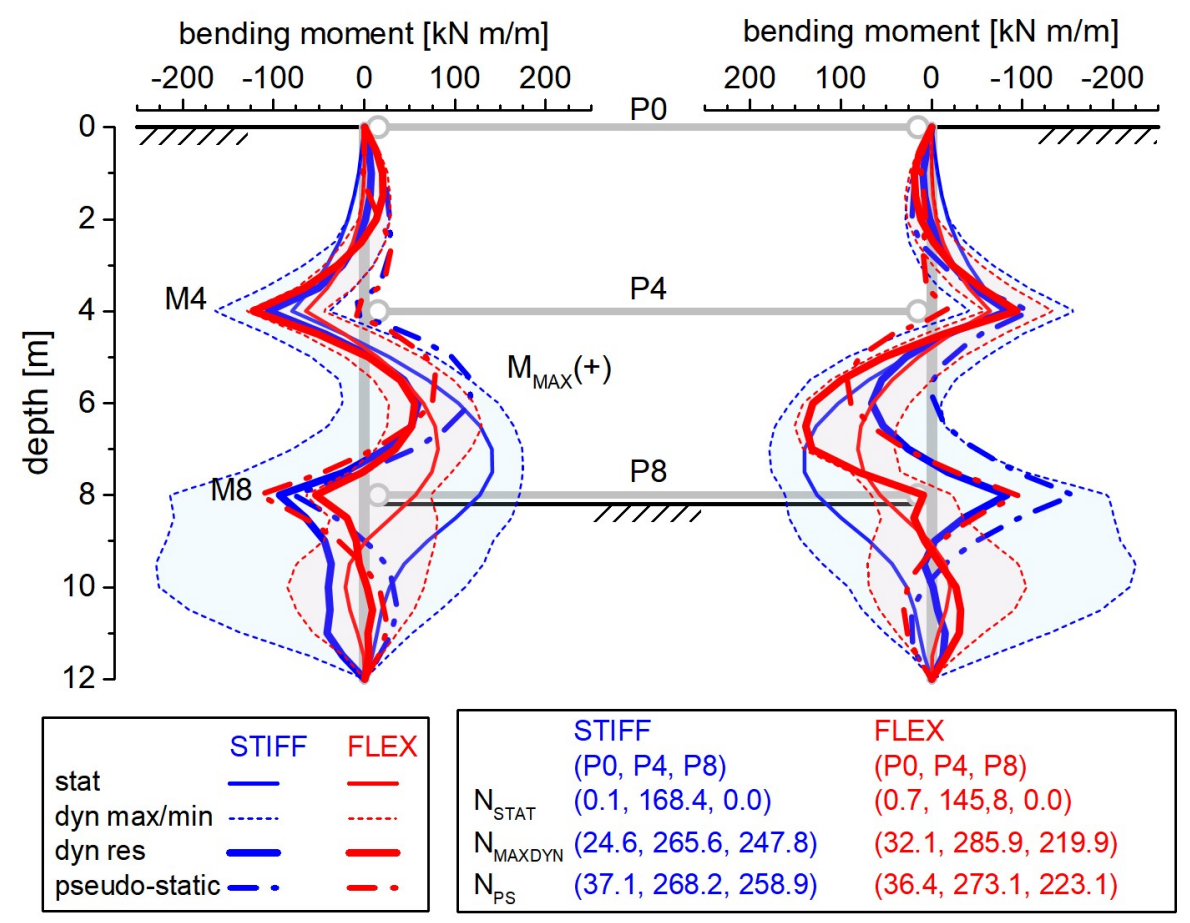

Fig. 4 Structural actions: static, dynamic and pseudo-static analyses 
The results of dynamic analyses are synthetically shown in Fig. 5 (peak values). Results of pseudo-static analyses are also shown in these figures. The evolution of structural stresses with increasing seismic actions evidences maximum bending moments moving towards negative values at prop levels (M4, M8). The three earthquakes give rise, for a given $a_{\mathrm{MAX}, F F}$, to somewhat different values of structural actions. These may be due a combined effect of the different frequency contents of the signals (see Fig. 2 and Tab. 1) and of amplification/deamplification in proximity of the structure rather than in the free-field (Soccodato and Tropeano, 2015).
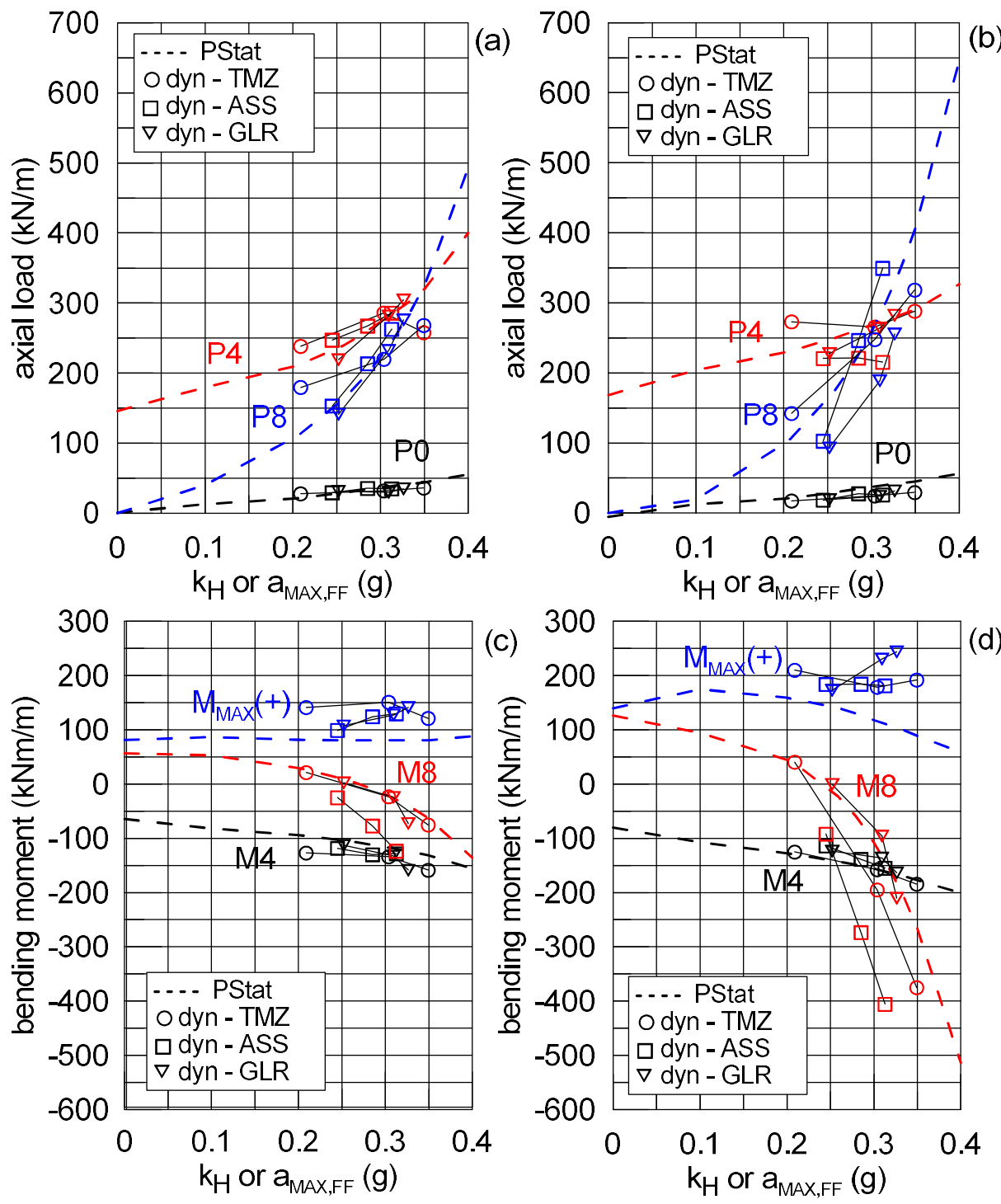

Fig. 5 Peak axial loads and bending moments: a) and c): flexible walls; b) and d): stiff walls 
It appears that, despite of the broad agreement observed for the general trends, peak bending moments (both positive and negative) predicted by numerical analyses are higher than those related to the pseudo-static analyses, especially for the stiff wall configuration; a slightly better agreement appears for the axial loads on props.

Post seismic structural actions are plotted in Fig. 6. Axial loads, especially for low values of ground acceleration, do not decrease significantly; a more pronounced reduction from peak to post seismic value is observed for maximum bending moments, in particular for the stiff walls (see for comparison Fig. 5).
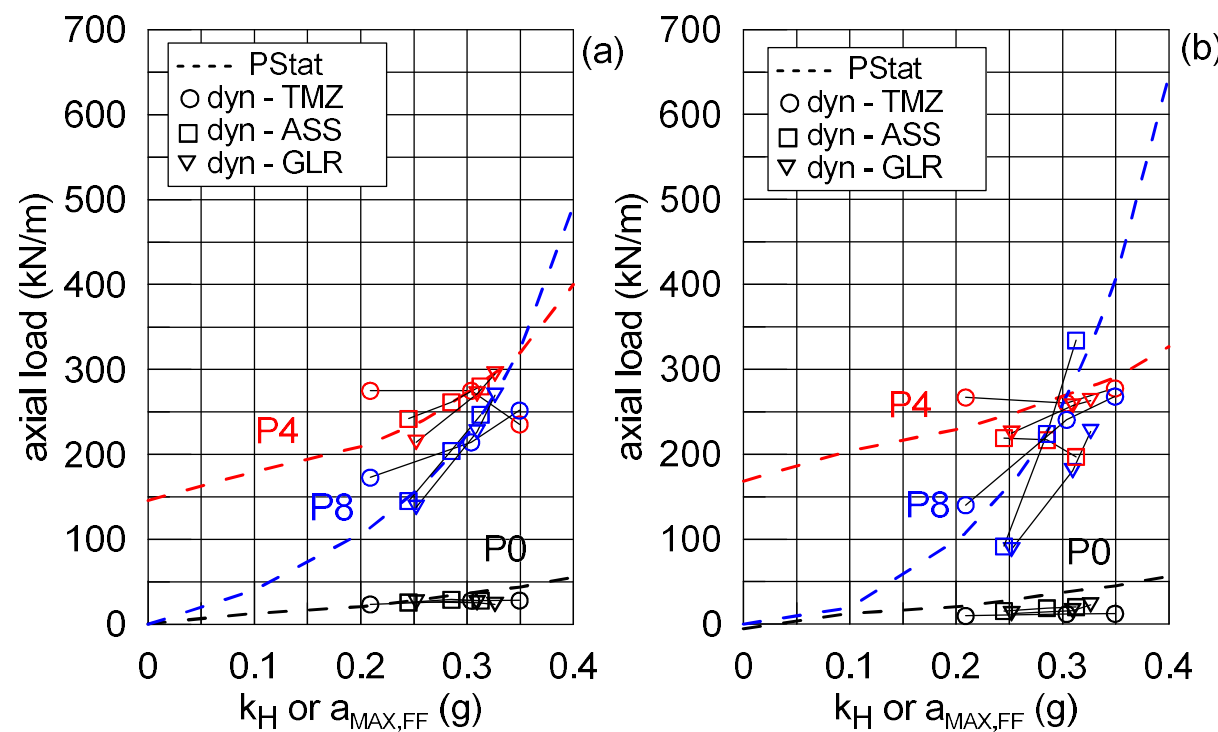

(b)
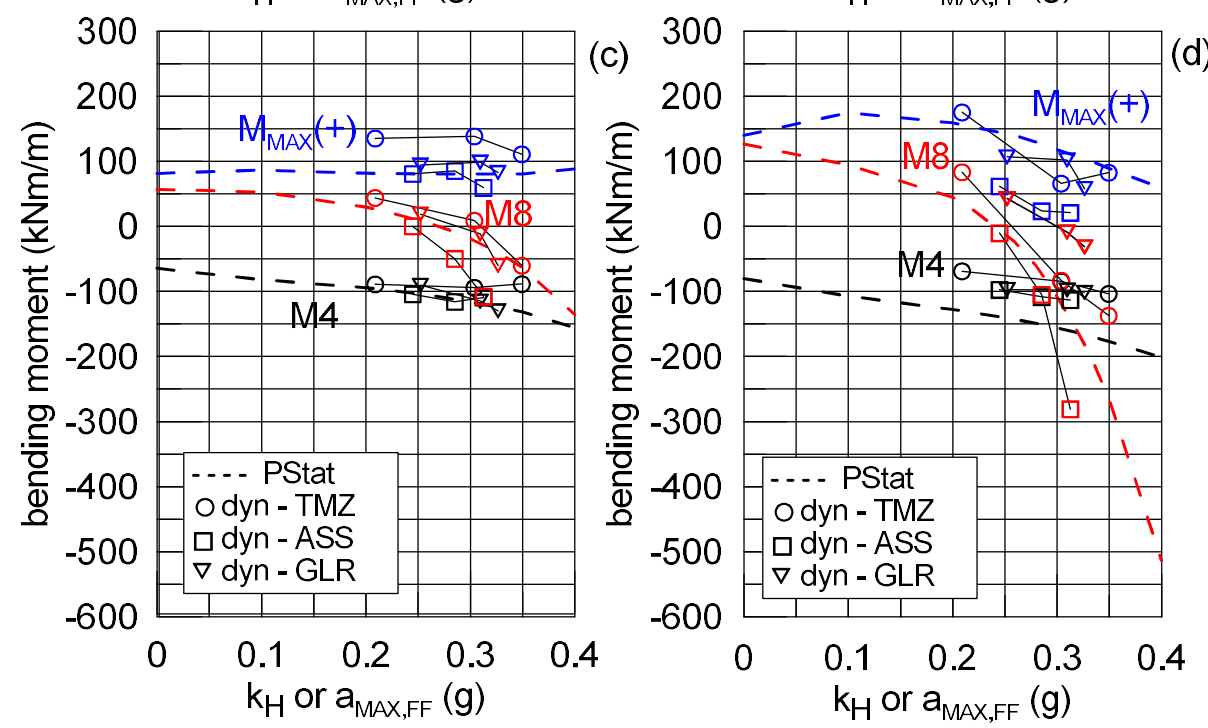

Fig. 6 Post seismic axial loads and bending moments: a) and c): flexible walls; b) and d): stiff walls 
Post seismic stress remain very large as compared to static condition: soil horizontal stresses are in fact significantly larger than those related to the active limit state existing at the end of excavation, under static condition.

Finally, the onset of the results of the analyses seems to indicate that the $a_{\mathrm{MAX}, F F}$ is not an effective motion parameters in order to evaluate the seismic performance of this kind of structure.

\section{Conclusions}

In the present study, the results of several dynamic numerical analyses of a multipropped retaining wall in a dry coarse soil have been presented and discussed.

The results of the analyses indicate that structural stresses (bending moments in walls and axial loads on props) may reach very large values and the maximum ground acceleration in the free field seems not to be an effective parameter in order to evaluate the seismic performance of this kind of retaining structures. Post seismic structural stresses remain very large as compared to the static condition.

\section{References}

Bahrami, M., Khodakarami, M.I., and Haddad, A. (2019). Seismic behavior and design of strutted diaphragm walls in sand. Computers and Geotechnics, 108, 85-87.

Callisto, L., and Soccodato, F.M. (2010). Seismic design of cantilevered retaining walls. Journal of Geotech. and Geoenv. Eng, 136(2), 344-354.

Chowdhury, S., Deb, K., and Sengupta, A. (2015). Behavior of undeground strutted retaining structure under seismic conditions. Earthquake and structures, 8(5), 1147-1170.

Conti, R., Madabhushi, G.S.P., and Viggiani, G.M.B. (2012). On the behaviour of flexible retaining walls under seismic actions. Geotechnique 62, 1081-1094.

Kuhlemeyer, R.L., and Lysmer, J. (1973). Finite Element Method accuracy for wave propagation problems. Journal of Soil Mechanics \& Foundations Division ASCE, 99(SM5), 421-427.

Itasca C.G. (2011). Fast Lagrangian Analysis of Continua. User's Guide. 5th Edition (FLAC Version 7.0)

Seed, H.B., and Idriss, I.M. (1970). Soil moduli and damping factors for dynamic analysis. Report No. EERC 70-10, University of California, Berkeley.

Soccodato, F.M., and Tropeano. G., (2015). The role of ground motion characters on the dynamic performance of propped retaining structures. Proc 6th International Conference on Earthquake Geotechnical Engineering (ICEGE 2015), Christchurch, New Zealand, Nov. 1-4.

Tropeano. G., and Soccodato, F.M. (2014). Dynamic analyses of propped retaining structures. Proc. 8th European Conf. on Numerical Methods in Geotechnical Engineering (NUMGE 2014), 2, pp 1193-1198. 